\title{
CORRIGENDUM
}

\section{Epistemic inclination and factualization: a synchronic and diachronic study on the semantic gradience of factuality - CORRIGENDUM}

\author{
VITTORIO TANTUCCI \\ Lancaster University
}

doi: http://dx.doi:10.1017/langcog.2014.34, Published by Cambridge University Press 10 November 2014.

On page 371 of Volume 7 (3), the sentence starting on line three of the abstract: "In this respect, the speaker/writer's increasing certainty upon the realization of an event or situation is here as factualization" should read "In this respect, the speaker/writer's increasing certainty of the realization of an event or situation is here seen as factualization".

Also, on page p.371 and 372: the word "subjected" should read as "subjectified"

REF E R EN C E

Tantucci, V. (2015). Epistemic inclination and factualization: a synchronic and diachronic study on the semantic gradience of factuality. Language and Cognition, 7(3), pp 371-414 doi:10.1017/langcog.2014.34 